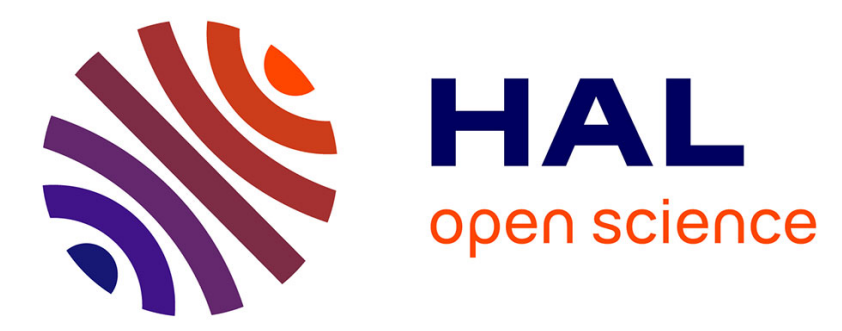

\title{
Modeling Penetration of Tide-Influenced Waves in Le Havre Harbor
}

Nicolas Guillou, Georges Chapalain

\section{To cite this version:}

Nicolas Guillou, Georges Chapalain. Modeling Penetration of Tide-Influenced Waves in Le Havre Harbor. Journal of Coastal Research, 2012, 283 (4), pp.945-955. 10.2112/JCOASTRES-D-11-00192.1 . hal-01674762

\section{HAL Id: hal-01674762 https://hal.science/hal-01674762}

Submitted on 3 Apr 2019

HAL is a multi-disciplinary open access archive for the deposit and dissemination of scientific research documents, whether they are published or not. The documents may come from teaching and research institutions in France or abroad, or from public or private research centers.
L'archive ouverte pluridisciplinaire HAL, est destinée au dépôt et à la diffusion de documents scientifiques de niveau recherche, publiés ou non, émanant des établissements d'enseignement et de recherche français ou étrangers, des laboratoires publics ou privés. 


\title{
Modeling Penetration of Tide-Influenced Waves in Le Havre Harbor
}

\author{
Nicolas Guillou* and Georges Chapalain \\ Centre d'Etudes Techniques Maritimes Et Fluviales (CETMEF) \\ Laboratoire de Génie Côtier et Environnement (LGCE) \\ 155 rue Pierre Bouguer Technopôle Brest Iroise - \\ BP 5 - 29280 Plouzané, France \\ Tél. : +33 (0)298056739 \\ Fax : +33(0)2 98056721 \\ E-mails : nicolas.guillou@developpement-durable.gouv.fr \\ georges.chapalain@developpement-durable.gouv.fr \\ * corresponding author
}

\begin{abstract}
The access channel to Le Havre harbor (France, English Channel) experiences significant tideinduced variation of wave height associated with current-refraction. The present study analyzes the penetration of these modulated waves in the harbor basin Hubert Raoul-Duval of the new Port 2000 infrastructures. A numerical approach is adopted on the basis of a phase-resolving model driven by external-predicted height, period and direction of approaching waves submitted to tide-induced variations. Numerical results of wave height are compared with field data collected at two wave buoys in the harbor-access channel and the inner basin. The propagation of tide-influenced waves within the harbor induces semi-diurnal variations of wave height in its inner basin with slight influence of local ambient tidal currents. Tide-influenced changes in the incident wave directions result in an increased exposition of the northern wharves at high tide and the eastern interior breakwater at low tide for the period of simulation. Finally, modeling is further exploited through a sensitivity study which analyzes different forcings of the model by external measurements at a single location in the entrance harbor channel.
\end{abstract}

\section{ADDITIONAL INDEX WORDS}

Bay of Seine, Port 2000, English Channel, agitation, ARTEMIS, TOMAWAC, TELEMAC

\section{INTRODUCTION}

Quantification of wave disturbances within harbor basins is of leading practical interest for authorities in planning, designing and operating construction of coastal structures, regulation of ship routing or dredging of entrance channels. Numerous modeling have been implemented to predict the interaction between waves and harbor structures as part of engineering studies (e.g., Abdellah, 2006; Triatmadja, 2010; Violante-Carvalho et al., 2009). The problem of excess wave agitation 
throughout the different design and construction phases of new harbor infrastructures is one of the main purpose of these studies (e.g., Chiang, 1988; Stratigaki et al., 2010).

Whereas modeling methods reliably predict refraction, diffraction, reflection and dissipation of waves within harbor basins (e.g., Panchang and Demirbilek, 2001), the question of incorporating tidal-currents is raised in areas characterized by strong wave and tidal hydrodynamics (e.g., Chen, Panchang and Demirbilek, 2005). Ambient currents create a Doppler shift and cause wave refraction, reflection and breaking, which can redistribute the overall wave energy and modulate the associated significant wave height. Tidal currents may thus modulate the wave agitation at the scale of the harbor basin. This effect is however superimposed on the modulation induced by the penetration of external tide-influenced waves within the harbor basin.

The purpose of the present study is to investigate the modulation induced by penetration of tide-influenced waves within the harbor basin relying on a comparison between numerical predictions and available measurements of the wave height. Effects of ambient currents on the wave agitation within the basin are not considered. The application is dedicated to the basin Hubert Raoul-Duval of the infrastructures of Port 2000 - Le Havre harbor located at the entrance of the Seine River in the English Channel (Figure 1). This research extends the numerical investigation conducted by Guillou and Chapalain (2012) on the tide-induced modulation of wave height in the outer Seine estuary. In the access channel to Port 2000, current-induced refraction is one of the main mechanism responsible for the tidal variation of the wave height increasing by about $30 \%$ and decreasing by about $10 \%$ its values.

Modeling relies on a phase-resolving model based on the extended mild-slope equation proposed by Booij (1981) and De Girolamo, Kostense and Dingemans (1988). The model is driven by tide-influenced wave components (significant wave height, period and direction) predicted by a regional phase-averaged model implemented at the scale of the outer Seine estuary. Spatial-varying water depths are also integrated at the scale of the harbor basin relying on numerical results issued from a depth-averaged circulation model. Whereas wave-current interactions are not integrated in the mild-slope equation, numerical results of the significant wave height reproduce field data collected with two wave buoys located at the entrance of the basin Hubert Raoul-Duval and the inner harbor, respectively. The increase of the wave height within the basin is further analyzed with respect to the semi-diurnal tidal cycle exhibiting recommendations for the ship routing regulation in the inner harbor. Finally, a sensitivity study is conducted to evaluate the possibility to drive the local wave agitation model by measurements in the entrance channel.

\section{MATERIALS AND METHODS}

\section{Experiment Description}

Measurements used here were obtained at three wave buoys H1 $\left(\lambda=0.104^{\circ} \mathrm{E}, \Phi=49.465^{\circ} \mathrm{N}\right)$, $\mathrm{H} 2\left(\lambda=0.087^{\circ} \mathrm{E}, \Phi=49.475^{\circ} \mathrm{N}\right)$ and $\mathrm{H} 3\left(\lambda=0.144^{\circ} \mathrm{E}, \Phi=48.459^{\circ} \mathrm{N}\right)$ in the access channel to Le Havre harbor and its inner basin (Figure 1-b). The wave buoys $\mathrm{H} 1$ and $\mathrm{H} 2$ were implemented in the access channel as part of an observational system to regulate the ship routing. The wave buoy H3 was set up to complete measurements in the inner harbor. The period analyzed here is the month of 
November 2008. It is characterized by a maximum significant wave height of $2.8 \mathrm{~m}$ in November 23, 2008 at point H1. The maximum tidal range reaches $7 \mathrm{~m}$ in November 14, 2008 at the tide gauge of the harbor. The maximum amplitude of the depth-averaged current in November 2008 is approached from numerical predictions of Guillou and Chapalain (2012) (Figure 2). Whereas current amplitude in November 2008 exceeds $1.5 \mathrm{~m} . \mathrm{s}^{-1}$ along the southern external breakwater and reaches $0.7 \mathrm{~m} . \mathrm{s}^{-1}$ at the harbor entrance, it decreases rapidly with maximum values below $0.4 \mathrm{~m} . \mathrm{s}^{-1}$ and $0.2 \mathrm{~m} . \mathrm{s}^{-1}$ in the western and eastern areas of the inner basin, respectively.
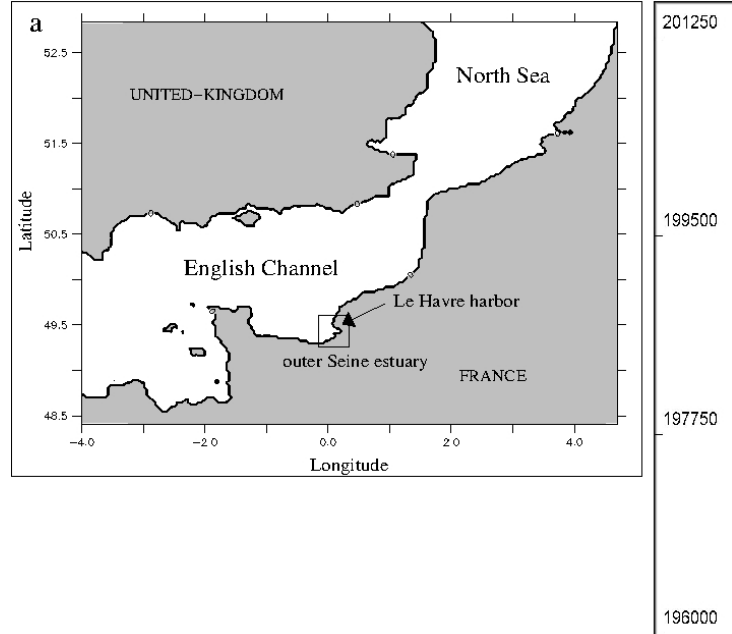

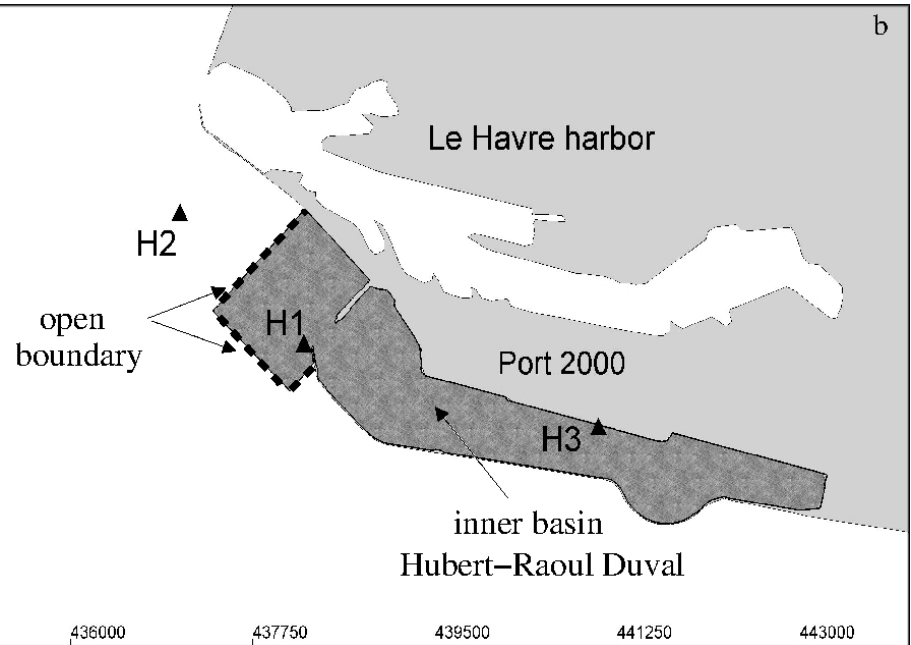

Figure 1: (a) Location of the harbor of Le Havre in the English Channel. (b) ARTEMIS computational domain (in dark grey) with the positions of wave buoys $\mathrm{H} 1, \mathrm{H} 2$ and $\mathrm{H} 3$. Coordinates are indicated in meters according to the French system "Lambert I Nord".

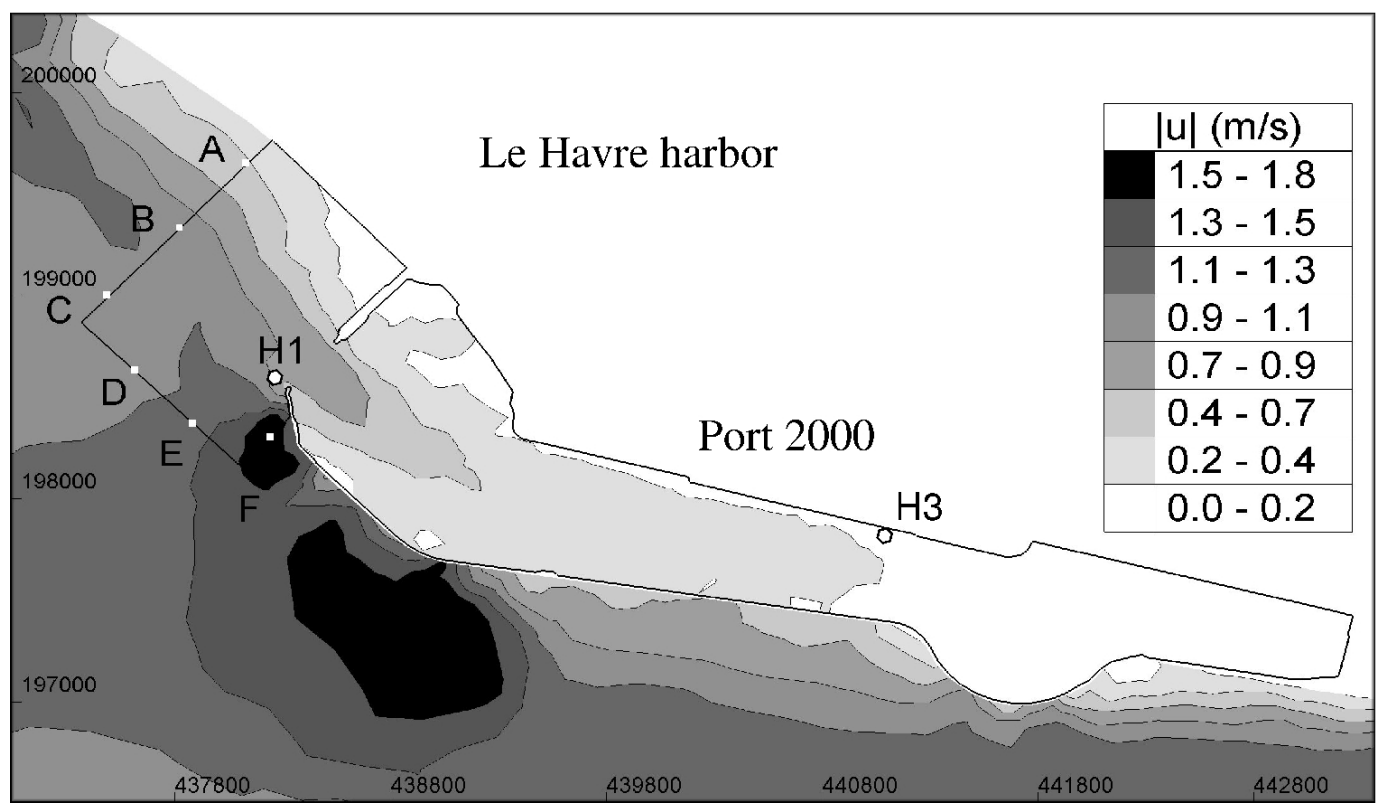

Figure 2: Predicted maximum amplitude of the depth-averaged current in November 2008 with the locations of points A-F along the boundary of ARTEMIS computational domain. 


\section{Model Description}

Modeling is based on the wave agitation model ARTEMIS (Agitation and Refraction with TElemac on a MIdSlope) (e.g., Aelbrecht, 1997; EDF R\&D, 2010) of the hydroinformatic finite elements system TELEMAC (EDF R\&D). It accounts for wave reflection, diffraction, refraction and dissipation by breaking and bottom friction for weak spatially-varying bathymetry.

Its application relies on few assumptions listed hereafter. The fluid is assumed ideal, incompressible and irrotational. Free-surface atmospheric stresses (pressure gradient and wind velocity) are neglected. Whereas numerical methods have been developed to integrate the effect of ambient currents for wave prediction within harbor basins (e.g., Chen, Panchang and Demirbilek, 2005), time-varying currents are not considered in the present modeling. This assumption allows the investigation of the single modulation associated with the penetration of tide-influenced waves with no superimposed local effects of ambient currents. The bottom is taken fixed and impervious. The wave height $H_{s}$ is assumed negligible compared to its wavelength $L\left(H_{s} / L<<1\right)$ and water depth $h$ $\left(\mathrm{H}_{\mathrm{s}} / \mathrm{h}<<1\right)$. Finally, the assumption of gentle slopes is considered in order to neglect evanescent waves $((\Delta \mathrm{h} / \mathrm{h}) /(\mathrm{h} / \mathrm{L})<<1)$.

ARTEMIS solves the extended mild-slope equation proposed by Booij (1981) and De Girolamo, Kostense and Dingemans (1988). The original equation of combined refractiondiffraction, derived by Berkhoff $(1972,1976)$ and Smith and Sprinks (1975) has been modified to integrate the dissipative processes associated with wave breaking and bottom friction. This development limits the increase of the wave height by shoaling in the field validity of the agitation model. The extended mild-slope equation is given in a horizontal Cartesian coordinate system $(x, y)$ by

$$
\nabla \cdot\left(C C_{g} \nabla \phi\right)+C C_{g}\left(k^{2}+i k \mu\right) \phi=0
$$

where $\phi$ is the complex reduced velocity potential, $C=\omega / k$ is the phase velocity, $C_{g}=\partial \omega / \partial k$ is the group velocity, $\omega$ is the wave frequency and $k$ is the wave number obtained with the dispersion relation. $\nabla$ and $\nabla$. are the gradient and divergence operators, respectively. The wave height $\mathrm{H}_{\mathrm{s}}$ is given by the mathematical expression

$$
H_{s}=\frac{2 \omega}{g}|\phi|
$$

where $g$ is the acceleration due to gravity. friction.

The dissipation coefficient $\mu$ (in $\mathrm{m}^{-1}$ ) parametrizes the processes of wave breaking and bottom

Dissipation through depth-induced wave breaking is computed according to Battjes and Janssen (1978). It is based on the analogy between wave breaking and hydraulic jump in terms of energy loss. The mathematical expression of $\mu$ is given by

where

$$
\mu=\frac{4 \alpha f_{p} Q_{b}}{C_{g}}\left(\frac{H_{m}}{H_{s}}\right)^{2}
$$




$$
H_{m}=\frac{0.88}{k} \tanh \left(\frac{\gamma_{s}}{0.88} k h\right)
$$

is the critical wave height at breaking line according to Miche (1944), $\gamma_{s}$ is taken equal to $\gamma_{s}=0.8$, $Q_{b}$ is the fraction of waves which are breaking, computed from a Rayleigh probability distribution of wave heights truncated at the critical value $H_{m}, f_{p}$ is the peak wave frequency and $\alpha$ is a weightening coefficient taken here equal to $\alpha=1$.

Dissipation through bottom friction is parametrized according to Putman and Johnson (1949). It is formulated assuming that the velocity may be derived from the first order Stokes wave potential solution. This leads to the following mathematical expression

$$
\mu=\frac{2}{3 \pi} \frac{f_{\omega} H_{s} \omega^{3}}{g C_{g} \sinh ^{3}(k h)}
$$

where $f_{\omega}$ is the friction factor taken equal to $f_{\omega}=0.001$.

Computation is performed in a mono-directional random mode. Wave energy spectrum is discretized in ten bands of equal energy delimited by frequencies ranging from 0.12 to $0.33 \mathrm{~Hz}$. The extended mild-slope equation is resolved for the ten associated wave spectra, reduced velocity potentials and significant wave heights. Numerical results are combined to provide the global solution of the significant wave height $H_{s}$.

The dissipation coefficient $\mu$ is computed with an iterative procedure to resolve the coefficient dependence on wave height and reduced velocity potential (Equations 3 and 5). ARTEMIS performs an initial computation neglecting dissipation by wave breaking and bottom friction $(\mu=0)$. This simulation results in a first estimation of the dissipation coefficient $\mu$. ARTEMIS performs then a second computation integrating the dissipation coefficient which supplies a second estimation of $\mu$. The procedure is iterated till convergence of predictions is achieved.

Finally, the numerical resolution is compelled to satisfy the criteria of a minimum mesh size compared to the wavelength. Whereas it is recommended to have a mesh size of $\Delta \mathrm{x}<\mathrm{L} / 7$, numerical applications provide satisfactory results for mesh-size constraints of $\Delta x<L / 4$.

Further details about the wave agitation model, its boundary conditions as well as its numerical resolution are available in ARTEMIS technical documentation (EDF R\&D, 2010).

\section{Model Setup}

ARTEMIS is implemented on a domain covering the inner basin of Le Havre harbor and its access channel (Figure 1-b). The dock has a length of $4200 \mathrm{~m}$ with a turning circle of $700 \mathrm{~m}$ in diameter at its center. The entrance southern channel has a width of $350 \mathrm{~m}$. Its average depth is 19 $\mathrm{m}$. The computational domain comprises 96415 nodes and 190584 finite elements with a mesh size of $\Delta \mathrm{x}=7 \mathrm{~m}$ compatible with the constraint $\Delta \mathrm{x}<\mathrm{L} / 4$ for wave periods of $3.5 \mathrm{~s}$ and water depths of $8 \mathrm{~m}$ in the inner basin.

Coastal boundary conditions are parametrized on the basis of the three key-parameters of reflection coefficient, direction of approaching waves and phase shift. The reflection coefficient represents a ratio of the amplitude of waves that approach a coast to the amplitude of waves 
reflected away from the coast. Whereas its values may be estimated on the basis of coastal structures design (slope and composition) and approaching waves components (wave height, period and direction) (e.g., Dickson, Herbers and Thornton, 1995; Shore Protection Manual, 1977), constant reflection coefficients are retained here on the basis of assumed references for various types of coastal boundaries (e.g., Thompson, Chen and Hadley, 1996). Reflection coefficient is set to 0.45 along external breakwaters to represent the wave attenuation by 8 tons accropodes distributed along a slope of $3 / 2$. Inner harbor structures present a slope of $3 / 2$. Reflection coefficient is thus set to 0.60 along inner structures composed of rocks of less than 1 ton. It is set to 0.80 along elements composed of concrete cubic blocks. This parametrization results in a reflection coefficient set to 0.60 almost everywhere in the inner basin except along the structures located in the northwestern area where it is set to 0.80 . Whereas numerous methods have been proposed to estimate the direction of approaching waves (Steward and Panchang, 2000), values are parametrized here in a simple manner on the basis of structures orientation in relation to the harbor entrance. Direction of approaching waves is considered normal to the external breakwaters and tangential in the shadow zone behind. It is set to an angle of $45^{\circ}$ along the southern breakwater and the northern wharves. Normal approaching waves are however considered in the north-western area and the eastern extremity of the basin. Finally, the phase shift is assumed to be zero as typically integrated (e.g., Isaacson, 1991; Pos, 1985).

A series of stationary computation of inner-harbor agitation is performed within the basin. The time interval has to be sufficiently small to approach the temporal evolution of tide-modulated wave height and large to avoid prohibitive computational time. A time interval of $1 \mathrm{~h} 30 \mathrm{~min}$ is chosen here. Open boundaries conditions (significant wave height, period and direction) and total water depth are integrated at every time step on the basis of numerical predictions of Guillou and Chapalain (2012) in the outer Seine estuary. This regional modeling was based on the coupling of the phase-averaged model TOMAWAC (Benoit, Marcos and Becq, 1996) with the depth-averaged circulation model TELEMAC 2D (Hervouet, 2003). Predictions successfully reproduced the tideinduced modulation of wave height in the access harbor channel at points $\mathrm{H} 1$ and $\mathrm{H} 2$ in November 2008 (Figure 3).

The present wave agitation modeling is however restricted to November 19-27, 2008 characterized by higher wave periods (Figure 4) to satisfy the mesh-size constraints of the numerical resolution. Furthermore, limiting the modeling time period avoids prohibitive demand on computer computational time and memory for the analysis of the numerical solutions.

Finally, differences between simulations and observations are quantified through the standard statistical parameters of bias (positive bias represent underestimates by the model), average of the absolute differences and root mean square error (RMSE). Mathematical expressions of each statistical parameter are given hereafter. If $X_{i}$ represents the measured value and $Y_{i}$ the simulated value for $i \in[1, n]$ with $n$ the number of data, the mentioned statistics can be defined with the following relationships:

$$
\begin{gathered}
\text { Bias }=\frac{\sum_{i=1}^{n}\left(X_{i}-Y_{i}\right)}{n} \\
\text { Meanabs }=\frac{\sum_{i=1}^{n}\left|X_{i}-Y_{i}\right|}{n}
\end{gathered}
$$


and

$$
R M S E=\sqrt{\frac{\sum_{i=1}^{n}\left(X_{i}-Y_{i}\right)^{2}}{n}}
$$
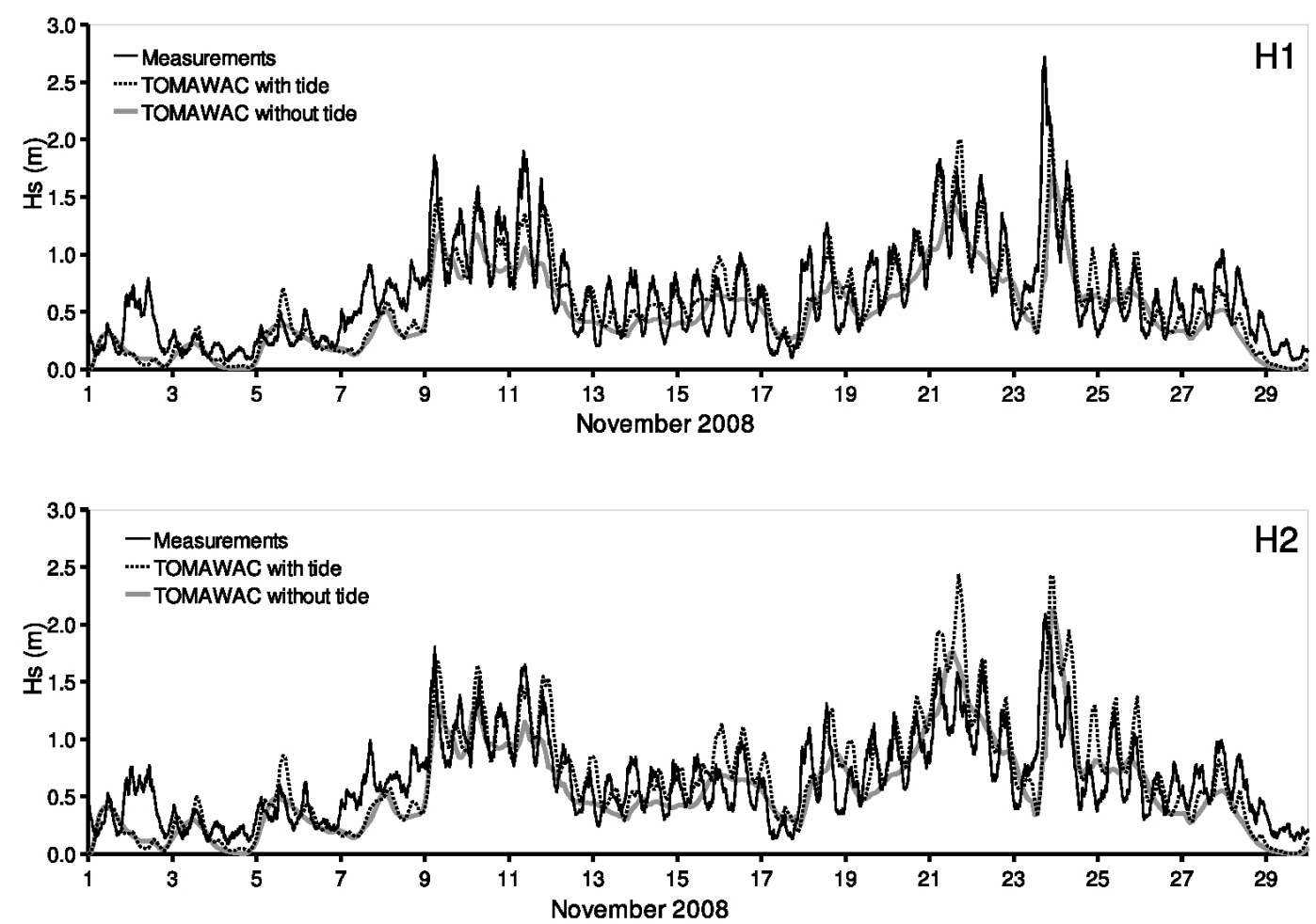

Figure 3: Measured and TOMAWAC computed time series of the significant wave height $\mathrm{H}_{\mathrm{s}}$ at locations H1 and H2 in November 2008 (from Guillou and Chapalain, 2012).

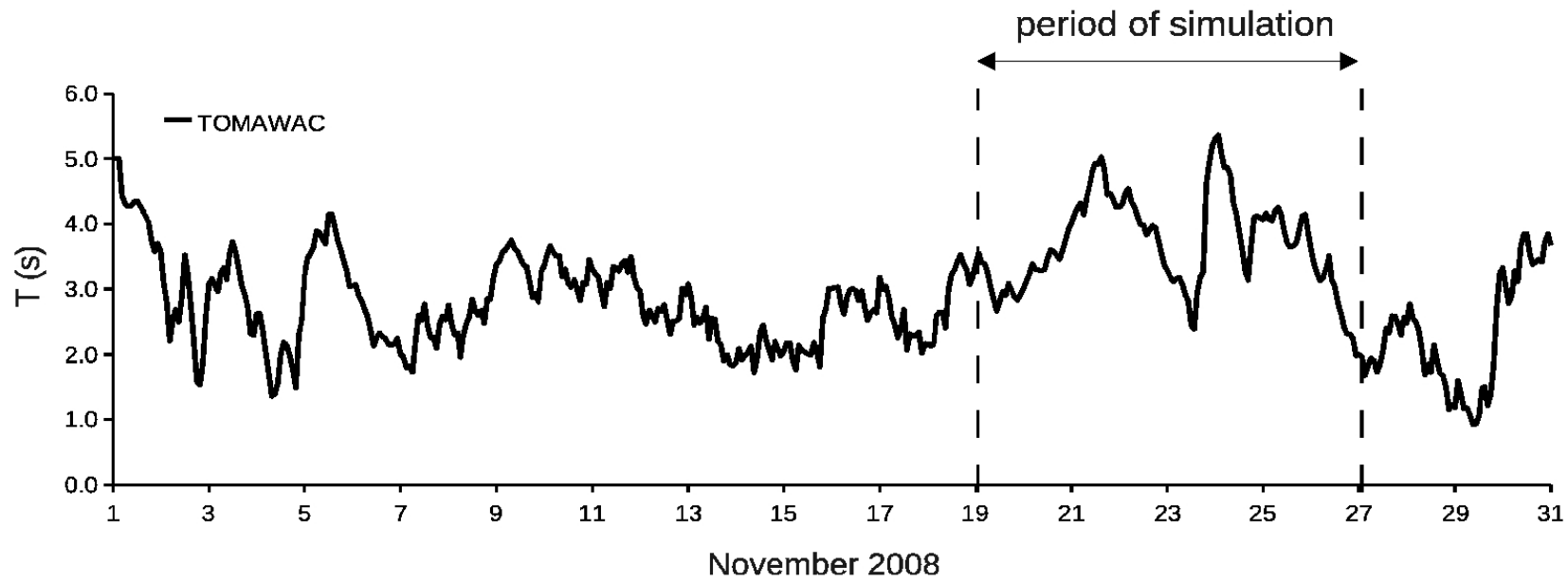

Figure 4: Computed time series of the peak period at location H1 in November 2008. 


\section{RESULTS AND DISCUSSION}

\section{Comparison of Model Predictions with Point Measurements}

ARTEMIS predicted time series of wave height are compared with measurements at points H1 and H3 (Figure 5). Numerical results reproduce the semi-diurnal modulation of the wave height from the entrance channel till the inner harbor. ARTEMIS predictions at point $\mathrm{H} 1$ are consistent with TOMAWAC numerical results (Figure 3) with a slight underestimation of the wave height during the storm of November 23, 2008. Numerical results reproduce the evolution of the significant wave height at point H3 while underestimating measurements at the beginning of the simulation from 19 to 20 November. Whereas maximum predicted storm wave height of November 23 falls in the range of observed values, it presents a 30 min-time lag compared to measurements. Nevertheless, stationary computations performed by ARTEMIS constitute a satisfactory numerical approach of the temporal evolution of wave-height conditions at the measurement site located within the harbor basin.
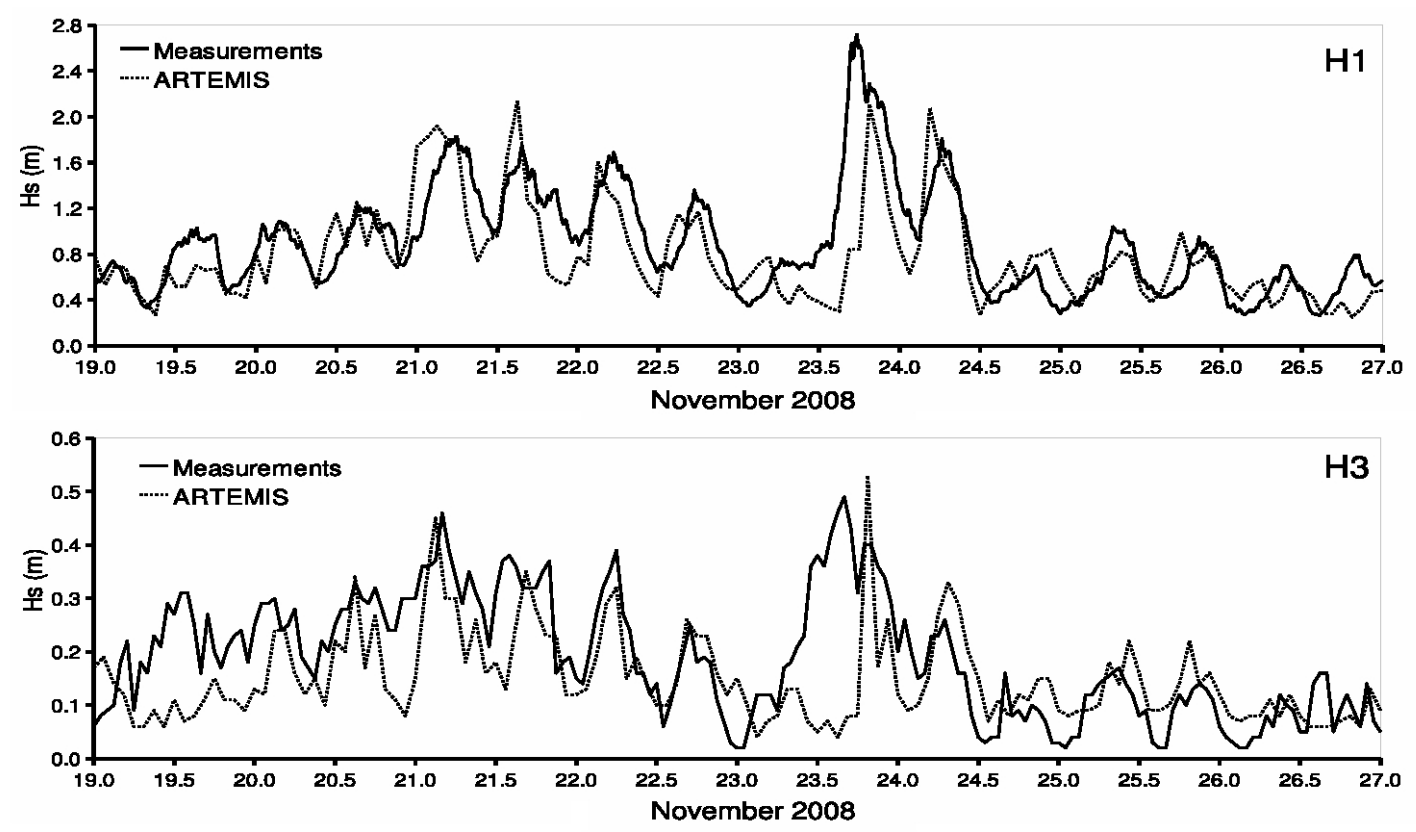

Figure 5: Measured and ARTEMIS computed time series of the significant wave height $\mathrm{H}_{\mathrm{s}}$ at locations H1 and H3 in November 19-27, 2008.

\section{Tidal Modulation of Wave Height Within the Harbor Basin}

Guillou and Chapalain (2012) have exhibited the significance of the tide on wind-generated surface-gravity waves in the outer Seine estuary and the access channel to Le Havre harbor. Current-induced refraction is one of the main mechanisms responsible for the semi-diurnal variation of the wave height in the access channel to Port 2000. Local ambient currents may thus have an impact on numerical predictions of wave height from the phase-resolving model ARTEMIS. 
Whereas the effects of the time-varying ambient currents are not integrated in the extended mildslope wave equation, the present numerical predictions reproduce the measured tidal modulation of wave height at point H3 (Figure 5). The observed semi-diurnal variation of wave height inside the harbor is thus mainly associated with the propagation of the outer tide-induced modulation in the access channel. This means also that local ambient currents have a negligible influence on the wave height within the harbor basin for the period of simulation in November 19-27, 2008.

Furthermore, outer modulations of the wave height are associated with changes in the approaching-wave direction through current-induced refraction (Guillou and Chapalain, 2012). The evolution of the wave direction presents a semi-diurnal modulation (Figure 6-a). For the period of simulation, major changes are obtained before slack tide (Figure 6-b) in relation to the spatial variation of current amplitude. Waves steepening has a slight influence on this modulation as maximum wave heights are obtained in following-currents conditions. During the period of simulation, current-induced refraction changes by 10-20 ${ }^{\circ}$ wave direction. South-easterly waves tend to deflect to the north just before high tide and to the south just before low tide in November 19-27, 2008. These variations of the wave direction modulate the exposure of the harbor-entrance channel increasing by about $30 \%$ and decreasing by about $10 \%$ the wave height at point $\mathrm{H} 1$ in the access harbor channel (Figure 6-b). A time-lag is however denoted between the modulations of the wave directions and heights for the period of simulation. This results in a close correlation between time series of outer wave height and free-surface elevation with maximum wave height at high tide and lowest values at low tide (Figure 6-b). Further details on the current-induced modulations of wave height in the access channel to the harbor of Le Havre are available in Guillou and Chapalain (2012).
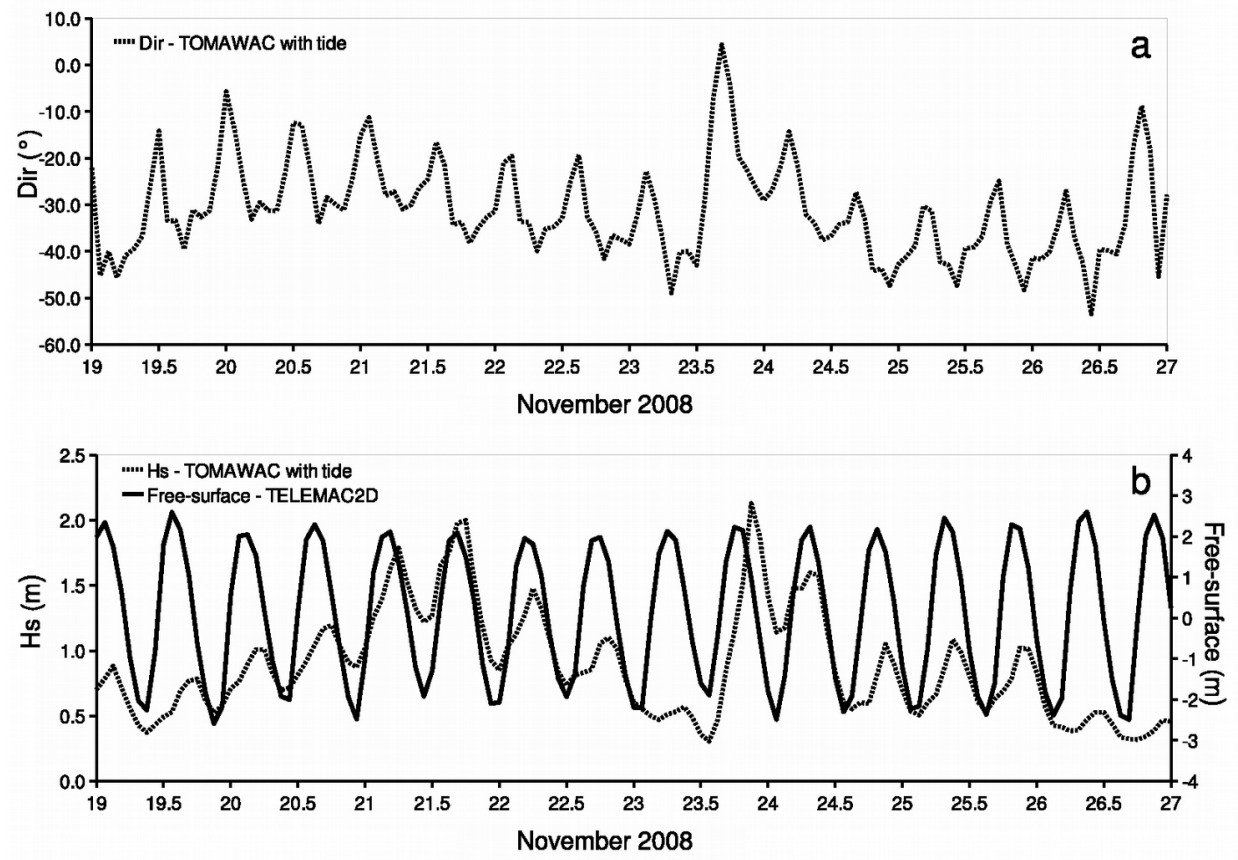

Figure 6: Computed time series of (a) the wave direction (anticlockwise from the east) and (b) the significant wave height $\mathrm{H}_{\mathrm{s}}$ and the free-surface elevation at location $\mathrm{H} 1$ in November 19-27, 2008. 
The consequences of this modulation on the wave agitation within the harbor are investigated displaying the predicted absolute maximum wave height in November 19-27, 2008 (Figure 7-a) and the maximum wave height at high (Figure 7-b) and low (Figure 7-c) tides during the period of simulation. Maximum wave heights within the harbor occur at high tide resulting in weak differences between Figures 7-a and 7-b. Waves of maximum heights enter the harbor along a south-eastern direction exposing the northern wharves at point \#1 and the southern breakwater at point \#2 with values reaching the threshold of $1.5 \mathrm{~m}$. Whereas the western part of the harbor basin experiences significant wave heights over $1.0 \mathrm{~m}$, the wave agitation in its eastern part is restricted to $0.9 \mathrm{~m}$ and $0.6 \mathrm{~m}$ in the turning circle used for ships manœuvrings. Maximum wave heights are naturally reduced at low tide as the outer wave height is reduced (Figure 7-c). Predictions are however exhibiting a slight deviation of the wave direction towards the south increasing the agitation in the eastern part of the southern breakwater at point \#3. Differences between Figures 7-b and 7-c are found to be related to the modulation of outer wave direction. Complementary processes such as diffraction between the two external breakwaters as well as reflection along the external northern wharves may also contribute to the predicted patterns of the wave deviation within the harbor.

\section{Sensitivity to a Single Forcing Point}

Numerical predictions are further exploited to evaluate the possibility to drive the wave agitation model by external measurements at a single location in the entrance channel. The method retained here consists in driving the wave agitation model by spatially uniform forcings derived from outer TOMAWAC simulation at a single location. A series of seven positions is retained corresponding to six points titled A to F evenly spaced along ARTEMIS open boundary and point $\mathrm{H} 1$ where measurement is operational (Figure 2). Time series of significant wave height, period and direction are extracted from TOMAWAC simulation at each location in November 19-27, 2008. Weak differences are denoted in the evolution of the wave components at points C, D, E and F. It is restricted to slight variations in the time series of the approaching wave directions. Four locations are thus retained to perform the sensitivity analysis: A, B, C and H1. ARTEMIS is successively driven by spatially-uniform forcings derived from TOMAWAC numerical results at these four locations in November 19-27, 2008. The four associated numerical predictions are estimated on the basis of local comparison with measurements at points $\mathrm{H} 1$ and H3. Table 1 compares the statistical results of the estimation of the wave height at these two measurement sites. Statistical parameters are also computed for the reference simulation of spatially-varying forcings along ARTEMIS open boundary (Figure 5). Positive biases are obtained in all simulations exhibiting the tendency of numerical predictions to slightly underestimate wave-height measurements at locations H1 and H3 in November 19-27, 2008. This tendency is associated with TOMAWAC predictions along the open boundary of ARTEMIS computational domain. Statistical parameters are to be considered in comparison with the range of wave height at each location. Reference predictions (Figure 5) are thus characterized by an average of the absolute differences of $0.26 \mathrm{~m}$ at point $\mathrm{H} 1$ where the wave height reaches $2.1 \mathrm{~m}$ and $0.084 \mathrm{~m}$ at point $\mathrm{H} 3$ where the wave height remains below $0.6 \mathrm{~m}$. This represents a relative difference of $10-15 \%$ at every measurement point. Predictions obtained with forcings at point A present the worst estimate of the wave height at both locations. Whereas numerical results obtained with forcings at point B fit fairly well with measurements at location H1, differences slightly increase at location H3 with an average of the absolute differences of $0.094 \mathrm{~m}$ 
and a root mean square error of $0.12 \mathrm{~m}$. Best results are obtained by driving ARTEMIS with predictions at points $\mathrm{C}$ and $\mathrm{H} 1$. The resulting average of the absolute differences and root mean square errors are similar to those obtained with spatially-varying forcings. Estimate of the bias are even better at both locations for simulation driven by forcings at point $\mathrm{C}$. These slight differences are exhibited displaying the predicted time series of the significant wave height at both measurement points (Figure 8).

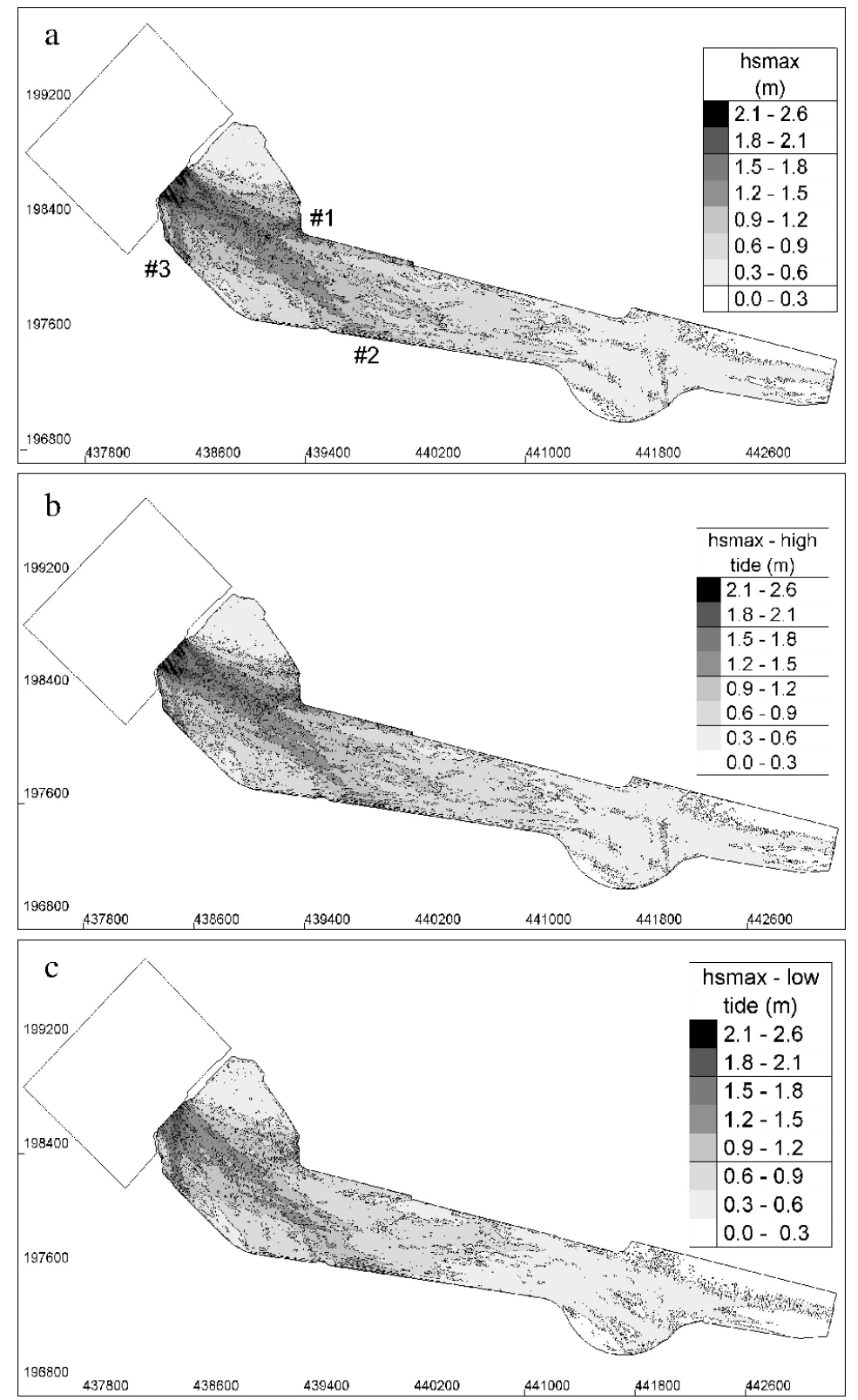

Figure 7: (a) ARTEMIS predicted maximum wave height $H_{s}$ in November 19-27, 2008 in the inner basin Hubert-Raoul Duval. Predicted maximum wave height $\mathrm{H}_{\mathrm{s}}$ at (b) high and (c) low tides in November 19-27, 2008. Numbers \#1, \#2 and \#3 indicate the locations along the southern breakwater and northern wharves preferentially exposed to the approaching waves. 
Further investigation is conducted displaying the predicted maximum wave height in November 19-27, 2008 from simulations driven by spatial uniform forcings at points C and H1 (Figure 9). Whereas wave agitation in the eastern part of the harbor basin is quite similar to initial numerical estimates (Figure 7), significant differences are exhibited at the western entrance. Predictions issued from simulation with forcings at point $C$ (Figure 9-a) are thus exhibiting a band with a width of $150 \mathrm{~m}$ directed towards the southern breakwater where the wave height exceeds 2.1 m. Simulation driven with forcings at point H1 (Figure 9-b) results in lower maximum wave height at the western harbor entrance. Predictions are however exhibiting a weaker exposition of the southern breakwater at point \#3 than in the reference situation (Figure 7). Time series of the waves components extracted from TOMAWAC simulation at points $\mathrm{C}$ and $\mathrm{H} 1$ vary mainly in the prediction of the approaching wave direction. Differences between Figures 9-a and 9-b may result from the sensitivity of model predictions to the direction imposed along the open boundary.

Numerical simulations underline the difficulty to drive the wave agitation model by external measurements at a single location. The present study has focused on short term comparison of numerical predictions with available measurements implemented as part of an observational system to regulate the ship routing. Further measurements are required to approach the variability of the approaching-wave direction along ARTEMIS open boundary and wave height in the western area of the harbor basin Hubert Raoul-Duval. In the present study, coupling with an offshore phaseaveraged model remains the most appropriate method to drive the wave agitation model.

Table 1: Statistical results of ARTEMIS estimation of wave height $\mathrm{H}_{\mathrm{s}}$ at points $\mathrm{H} 1$ and $\mathrm{H} 3$ with various open boundary conditions.

\begin{tabular}{llrrr}
\hline \hline & $\begin{array}{l}\text { ARTEMIS } \\
\text { boundary } \\
\text { conditions }\end{array}$ & $\begin{array}{r}\text { Bias } \\
(\mathrm{m})\end{array}$ & $\begin{array}{r}\text { Meanabs } \\
(\mathrm{m})\end{array}$ & $\begin{array}{r}\text { RMSE } \\
(\mathrm{m})\end{array}$ \\
\cline { 2 - 5 } $\begin{array}{l}\text { points of the } \\
\text { Results } \\
\text { at point }\end{array}$ & point A & 0.10 & 0.26 & 0.37 \\
H1 & point B & 0.20 & 0.35 & 0.45 \\
& point C & 0.09 & 0.28 & 0.39 \\
& point H1 & 0.07 & 0.28 & 0.39 \\
\cline { 2 - 5 } & points of the & 0.11 & 0.26 & 0.36 \\
Results & boundary & 0.039 & 0.084 & 0.11 \\
H3 & point A & 0.101 & 0.110 & 0.14 \\
& point B & 0.045 & 0.094 & 0.12 \\
& point C & 0.014 & 0.085 & 0.11 \\
& point H1 & 0.034 & 0.087 & 0.11 \\
\hline
\end{tabular}



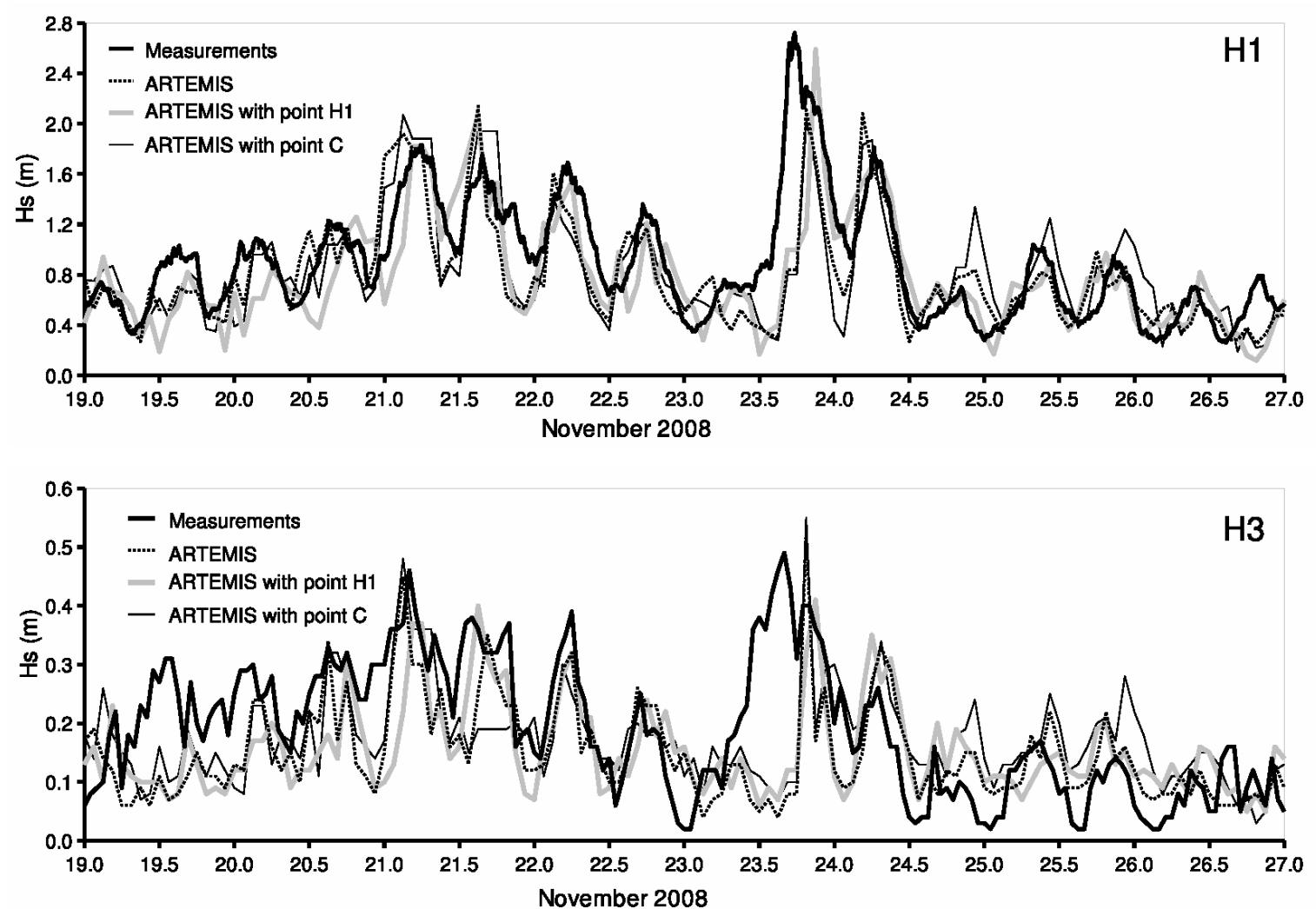

Figure 8: Measured and ARTEMIS computed time series of the significant wave height $\mathrm{H}_{\mathrm{s}}$ at locations H1 and H3 in November 19-27, 2008. Simulations are performed with spatial-varying and spatial-uniform forcings extracted from TOMAWAC simulation at locations C and H1.

\section{CONCLUSIONS}

A phase-resolving model coupled with a regional phase-averaged model has been used to investigate the penetration of waves submitted to tide-induced modulations within Le Havre harbor. Numerical predictions have been compared with measurements in the harbor access channel and the eastern part of its inner basin. The main outcomes of the present study are the following.

(1) Computed time series of wave height reproduce the observed evolution at the two wave buoys $\mathrm{H} 1$ and $\mathrm{H} 3$ located in the access harbor channel and its inner basin, respectively. Comparison exhibits the negligible influence of local ambient currents on the wave height in the eastern part of the harbor basin for the period of simulation. The observed semi-diurnal variations of the wave height within the harbor are found to be mainly associated with the propagation of the outer tide-induced modulation in the access channel.

(2) Increase of the wave height within the basin is analyzed with respect to the semi-diurnal tidal cycle. Predictions exhibit an increase exposition of the northern wharves at high tide and the southern western breakwater at low tide for the period of simulation in relation to current- 
induced refraction of approaching waves.

(3) Driving the wave agitation model by external measurements at a single location gives a first estimate of the hydrodynamic condition in the eastern part of the harbor basin. This method suffers however from the sensitivity of model predictions to the approaching-wave directions in the western area close to the harbor entrance.

A prospective of these research will consist in extending the simulation period to produce on the basis of further comparison with measurements accurate estimate of wave agitation condition within the basin Hubert Raoul-Duval. Long-term modeling will help to establish a map of average and extreme wave conditions within the harbor. This results will help the harbor authorities to regulate the ship manœuvrings and routing. Increasing the model accuracy will also participate to the estimate of wave run up and overtopping on coastal harbor structures.
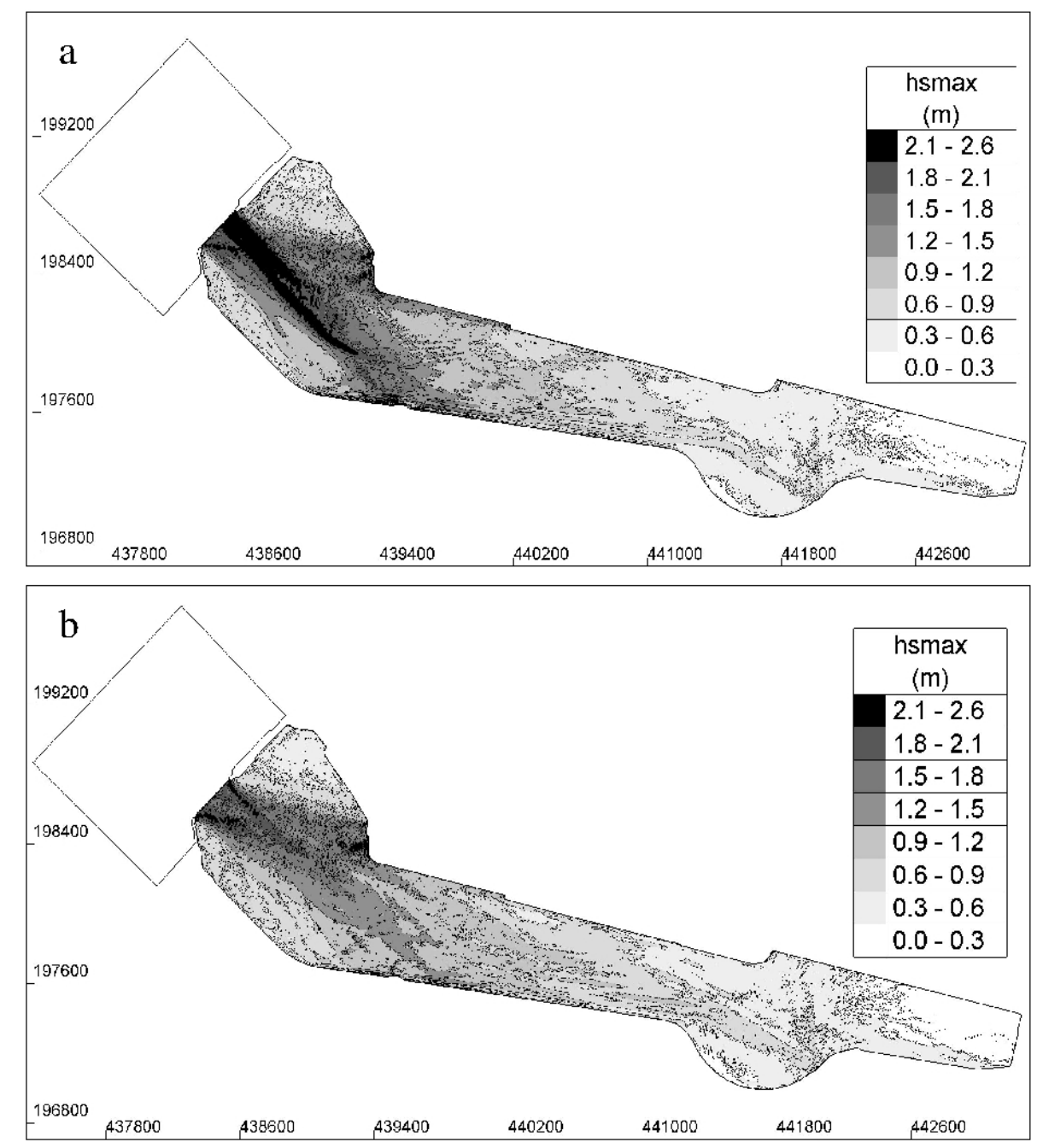

Figure 9: ARTEMIS predicted maximum wave height $H_{s}$ in November 19-27, 2008 in the inner basin Hubert-Raoul Duval from simulations driven by spatial uniform forcings at points (a) C and (b) $\mathrm{H} 1$. 


\section{ACKNOWLEDGMENTS}

We are particularly grateful to Ronan Schubel (Grand Port Maritime du Havre, France) for providing us with bathymetry and wave buoys measurements on the harbor computational domain. The present paper is a contribution to the CETMEF-IUEM joint research program MEMPHYS (Mesure Et Modélisation des Processus HYdrodynamiques et hydro-Sédimentaires dans les écosystèmes côtiers) (http://memphys-lgce.fr.ht).

\section{LITERATURE CITED}

Abdellah, A.M., 2006. Simulation of wave propagation in the eastern harbor of Alexandria, Egypt. Egyptian Journal of Aquatic Research, vol. 32, n¹, 48-60.

Aelbrecht, D., 1997. ARTEMIS 3.0: a finite element model for predicting wave agitation in coastal areas and harbours including dissipation. In: Computer modelling of seas and coastal regions III. International conference. Eds.: J.R. Acinas and C.A. Brebbia, 343-352.

Battjes, J.A. and Janssen, J.P.F.M., 1978. Energy loss and set-up due to breaking of random waves. $16^{\text {th }}$ International Conference of Coastal Engineering, 569-587.

Benoit, M.; Marcos, F. and Becq, F., 1996. Development of a third generation shallow-water wave model with unstructured spatial meshing. Proceedings of the $25^{\text {th }}$ International Conference on Coastal Engineering, 465-478.

Berkhoff, J.C.W., 1972. Computation of Combined Refraction-Diffraction. Proc. $13^{\text {th }}$ Int. Conf. on Coastal Engineering, ASCE, Vancouver, Canada.

Berkhoff, J.C.W., 1976. Mathematical Models for Simple Harmonic Linear Water Waves. Wave Refraction and Diffraction, Publ. n¹63, Delft Hydraulics Laboratory, Delft, The Netherlands.

Booij, N., 1981. Gravity waves on water with non-uniform depth and current. PhD thesis, Technical University of Delft, The Netherlands, 130 pp.

Chen, W.; Panchang, V. and Demirbilek, Z., 2005. On the modeling of wave-current interaction using the elliptic mild-slope wave equation. Ocean Engineering, 32, 2135-2164.

Chiang, W.-L., 1988. Modelling long and intermediate waves in a harbor. Applied Mathematical Modelling, vol. 12, 423-428.

De Girolamo, P., Kostense, J.K. and Dingemans, M.W., 1988. Inclusion of wave breaking in a mildslope model. Comput. Modell. Ocean Eng., 221-229.

Dickson, W.S.; Herbers, T.H.C. and Thornton, E.B., 1995. Wave reflection from breakwater. Journal of Waterway, Port, Coastal and Ocean Engineering, 121 (5), 262-268.

EDF R\&D, 2010. Agitation d'un plan d'eau par la houle. Logiciel ARTEMIS. Version 6. Notice théorique et manuel utilisateur. $134 \mathrm{pp}$.

Guillou, N. and Chapalain, G. (2012). Modeling the Tide-Induced Modulation of Wave Height in the Outer Seine Estuary. Journal of Coastal Research.doi: http://dx.doi.org/10.2112/JCOASTRES- 


\section{D-11-00075.1}

Hervouet, J.M., 2003. Hydrodynamique des écoulements à surface libre. Modélisation numérique avec la méthode des éléments finis. Presses de l'Ecole Nationale des Ponts et Chaussées, Paris, 311 pp.

Isaacson, M., 1991. Measurement of regular wave reflection. Journal of Waterway, Port, Coastal and Ocean Engineering, 117 (6), 553-569.

Miche, R., 1944. Mouvements ondulatoires de la mer en profondeur croissante ou décroissante, forme limite de la houle lors de son déferlement. Application aux digues maritimes. Troisième partie. Forme et propriétés des houles limites lors du déferlement. Croissance des vitesses vers la rive. Annales des Ponts et Chaussées, Tome 114, 369-406.

Panchang, V.G. And Demirbilek, Z., 2001. Simulation of waves in harbors using two-dimensional elliptic equation models. In: Liu, P. L.-F. (Ed.), Advances in Coastal and Ocean Engineering, vol. 7. World Scientific, 125-162.

Pos, J.D., 1985. Asymmetrecial breakwater gap wave diffraction using finite and infinite elements. Coastal Engineering, 9, 101-123.

Putman, J.A. and Johnson, J.W., 1949. The dissipation of wave energy by bottom friction. Trans. Amer. Geophys. Union, 30 (1), 67-74.

Smith, R. and Sprinks, T., 1975. Scattering of surface waves by a conical island. Journal of Fluid Mechanics, 72, Part 2, 373-384.

Steward, D.R. and Panchang, V.G., 2000. Improved coastal boundary condition for surface water waves. Ocean Engineering, 28, 139-157.

Stratigaki, V.; Vanneste, D.; Troch, P.; Gysens, S. and Willems, M., 2010. Numerical modeling of wave penetration in Ostend harbour. Proceedings of the $32^{\text {nd }}$ International Conference on Coastal Engineering, Shangai, China. 1-15.

Thompson, E.F.; Chen, H.S. and Hadley, L.L., 1996. Validation of numerical model for wind waves and swell in harbors. Journal of Waterway, Port, Coastal and Ocean Engineering, 122 (5), 245-257.

Triatmadja, R., 2010. Numerical modeling of wave propagation into a harbor using improved characteristic scheme. Journal of Hydro-environment Research, 4, 143-151.

U.S. Army Coastal Engineering Resource Centre, 1977. Shore Protection Manual. Third Edition. Vol. 1.

Violante-Carvalho, N., Paes-Leme, R.B., Accetta D.A. and Ostritz F., 2009. Diffraction and reflection of irregular waves in harbor employing a spectral model. Annals of the Brazilian Academy of Sciences. 81 (4), 837-848.

\section{RESUME}

Les hauteurs de houle dans le chenal d'accès au port du Havre (France, Manche) sont influencées par la marée à travers le phénomène de réfraction par les courants. La présente étude analyse la propagation de cette modulation dans le bassin portuaire Hubert Raoul-Duval des nouvelles infrastructures de Port 2000. Une approche numérique est adoptée sur la base d'un modèle 
à résolution de phase forcé par les prédictions externes des hauteurs, périodes et directions de la houle soumises à l'influence de la marée. Les prédictions numériques de la hauteur de houle sont comparées aux observations de deux houlographes disposés dans le chenal d'accès à Port 2000 et son bassin portuaire. La propagation des houles modulées par la marée à l'intérieur du port induit des variations semi-diurnes de la hauteur de houle dans le bassin portuaire avec une influence négligeable des courants de marée locaux. Les changements de la direction de la houle incidente induits par la marée conduisent à une exposition accrue du quai nord à marée haute et de l'extrémité est de la digue de protection à marée basse au cours de la période de simulation. Enfin, la modélisation est exploitée à travers une étude de sensibilité destinée à analyser la possibilité de forcer le modèle d'agitation par des mesures ponctuelles réalisées au niveau du chenal d'accès au port. 